\section{Reliability of core needle biopsy as a second-line procedure in thyroid nodules \\ with an indeterminate fine-needle aspiration report: a systematic review and meta-analysis}

Pierpaolo Trimboli, Luca Giovanella

Department of Nuclear Medicine and Thyroid Centre, Oncology Institute of Southern

Switzerland, Bellinzona, Switzerland

Purpose: This study was undertaken to summarize the published data and to provide more robust estimates regarding the issue of core needle biopsy (CNB) for discriminating thyroid nodules with indeterminate fine-needle aspiration (FNA) results.

Methods: The systematic review was conducted according to the Preferred Reporting Items for Systematic Reviews and Meta-Analyses (PRISMA) guidelines. The sources comprised studies published through November 2017. Original articles that investigated CNB in indeterminate thyroid lesions were searched. A random-effects model was used for statistical pooling of the data. The $I^{2}$ index was used to quantify the heterogeneity among the studies. The Egger test was carried out to evaluate the possible presence of significant publication bias. Quality assessment of the studies was performed according to QUADAS-2.

Results: A total of 205 articles were retrieved, seven were initially selected, and the data of five papers were ultimately pooled in a meta-analysis. The overall cancer rate was $34 \%$. The rate of cancers correctly diagnosed by CNB was $83 \%$ (95\% confidence interval [CI], 76 to 89), with neither heterogeneity $\left(I^{2}=25 \%\right)$ nor publication bias (Egger test, $\left.\mathrm{P}=0.918\right)$. The rate of benign nodules correctly assessed by CNB was $84 \%(95 \% \mathrm{Cl}, 65$ to 97$)$, with significant heterogeneity $\left(I^{2}=93.4 \%\right)$ and publication bias (Egger test, $\left.\mathrm{P}=0.016\right)$.

Conclusion: Evidence was found that CNB can correctly diagnose the majority of nodules previously read as indeterminate on FNA.

Keywords: Thyroid; Biopsy, large-core needle; Biopsy, fine-needle; Cytology; Thyroid neoplasms

\section{Introduction}

Fine-needle aspiration (FNA) cytology is a major tool used to evaluate thyroid nodules $[1,2]$. However, a non-negligible portion of thyroid lesions that undergo FNA are read as indeterminate thyroid nodules, which represent the gray zone of cytology [3]. The monotonous cellular population
ULTRA

SONO



META-ANALYSIS

https://doi.org/10.14366/usg. 17066 pISSN: 2288-5919 • elSSN: 2288-5943

Ultrasonography 2018;37:121-128

Received: November 26, 2017

Revised: December 30, 2017

Accepted: January 2, 2018

Correspondence to:

Pierpaolo Trimboli, MD, Department

of Nuclear Medicine and Thyroid

Centre, Oncology Institute of Southern

Switzerland, Via Ospedale 12, 6500

Bellinzona, Switzerland

Tel. +41-091-8116446

Fax. +41-091-8116444

E-mail: pierpaolo.trimboli@eoc.ch

This is an Open Access article distributed under the terms of the Creative Commons Attribution NonCommercial License (http://creativecommons.org/ licenses/by-nc/3.0/) which permits unrestricted noncommercial use, distribution, and reproduction in any medium, provided the original work is properly cited.

Copyright (C) 2018 Korean Society of Ultrasound in Medicine (KSUM)

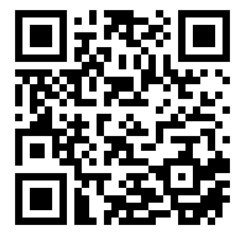

How to cite this article:

Trimboli P, Giovanella L. Reliability of core needle biopsy as a second-line procedure in thyroid nodules with an indeterminate fineneedle aspiration report: a systematic review and meta-analysis. Ultrasonography. 2018 Apr;37(2):121-128. 
combined with scant or absent colloid, as observed in these thyroid cytologic samples, does not allow the discrimination of malignant and benign lesions [3]. In these cases, international guidelines $[2,4]$ recommend evaluating almost all patients through diagnostic surgery. In histologic analyses of surgical samples, the large majority (i.e., 70\%-80\%) of thyroid nodules with indeterminate FNA results is benign [5]; therefore, the identification of parameters or features that could serve as potential markers of malignancy would be of great clinical value. Several molecular, cytologic, ultrasonographic, and clinical studies have investigated such parameters, with controversial findings [6-10]. Recently, some papers have reported that microhistologic examinations by core needle biopsy (CNB) can diagnose a large percentage of indeterminate thyroid nodules, and this technical approach has entered into use throughout the world [11]. Of particular importance in clinical practice, diagnostic surgery can be avoided in cases of thyroid nodules that are read as benign on CNB; in addition, a very low rate of minor complications from CNB has been recorded, with good comfort for patients [12]. More recently, the Task Force Committee of the Korean Society of Thyroid Radiology (KSThR) developed the first guidelines on CNB containing evidence-based recommendations [13]. To date, no strong evidence exists regarding the specific use of CNB in thyroid nodules cytologically classified as indeterminate. Thus, while some clinicians' guidelines have introduced CNB as a second-line biopsy technique in thyroid nodules with inadequate FNA reports [1], the use of CNB in lesions with indeterminate cytology is still not recommended. The objective of the present study was to conduct a systematic review and meta-analysis of published data on the diagnostic performance of CNB as a second-line biopsy technique in patients with previous indeterminate thyroid nodules according to FNA cytology. Thereby, we aimed to provide more robust estimates regarding this issue.

\section{Materials and Methods}

\section{Conduct of the Systematic Review}

The present systematic review was conducted in accordance with the Preferred Reporting Items for Systematic Reviews and MetaAnalyses (PRISMA) guidelines [14]; the PRISMA checklist can be found in the Supplementary Table 1.

\section{Search Strategy}

A comprehensive computer-based literature search of the PubMed/ MEDLINE and Scopus databases was conducted. Initially, we aimed to identify the largest possible number of papers reporting the use of CNB in nodules with prior indeterminate cytology. Then, we searched for studies evaluating the accuracy of CNB in thyroid nodules, and the initial search algorithm comprised the following terms: thyroid, core, needle and biopsy, thyroid nodule (MeSH), and biopsy, large-core needle (MeSH). A beginning date limit was not used, the search extended through November 25, 2017, and no language restriction was used. To identify additional studies and expand our search, the references of the retrieved articles were also screened.

\section{Study Selection}

Original articles that investigated CNB in indeterminate thyroid nodules after FNA were eligible for inclusion. The main exclusion criteria were articles that did not provide clear study characteristics and reports with overlapping patient data. Importantly, all cases reported in the studies with no histologic follow-up were excluded.

Table 1. Main characteristics of the studies retrieved through a systematic review of the literature

\begin{tabular}{|c|c|c|c|c|c|c|c|c|}
\hline Reference & Journal & Year & Period of enrollment & Country & Study type & $\begin{array}{l}\text { Cytology reporting } \\
\text { system }^{\text {a) }}\end{array}$ & FNA category & $\begin{array}{l}\text { Nodules with } \\
\text { histologic } \\
\text { follow-up }\end{array}$ \\
\hline Park et al. [15] & Head Neck & 2011 & Feb 2005-Jun 2009 & Korea & Pro & Not detailed & Indeterminate & 53 \\
\hline Na et al. [16] & Thyroid & 2012 & Feb 2009-Jan 2010 & Korea & Pro & Bethesda & AUS/FLUS & 104 \\
\hline Nasrollah et al. [17] & Endocrine & 2013 & Dec 2011-May 2012 & Italy & Retro & SIAPEC-IAP & TIR 3 & 40 \\
\hline Choi et al. [18] & Thyroid & 2015 & Jan 2011-Dec 2012 & Korea & Retro & Bethesda & AUS/FLUS & 159 \\
\hline Na et al. [19] & EurThyroid J & 2015 & Feb 2010-Jun 2013 & Korea & Retro & Bethesda & AUS/FLUS & 91 \\
\hline Trimboli et al. [20] & Endocrine & 2016 & Jun 2012-Dec 2013 & Italy & Retro & SIAPEC-IAP & TIR 3 & 74 \\
\hline Han et al. [21] & Eur J Neuroradiol & 2016 & Apr 2006-Dec 2010 & Korea & Retro & Bethesda & Indeterminate & 61 \\
\hline
\end{tabular}

This table does not include the five excluded studies: four studies were excluded due to unclear data [27-30], while the study of Choi et al. [26] was excluded due to potential overlap of the period of enrollment (from October 2008 to July 2011) with that of another series [22].

FNA, fine-needle aspiration; Pro, prospective; AUS/FLUS, atypia of undetermined significance/follicular lesion of undetermined significance; Retro, retrospective; SIAPECIAP, Societá Italiana di Anatomia Patologica e Citologia diagnostica - Divisione Italiana della International Academy of Pathology (the Italian consensus for thyroid cytology classification); TIR 3, category 3 in the five-tiered system for FNA cytology.

${ }^{\text {a) }}$ System adopted to classify thyroid nodules on initial cytology. 
The two authors independently reviewed the titles and abstracts of the retrieved articles, applying the inclusion and exclusion criteria previously described. Then, the same two researchers independently reviewed the full text of the remaining articles to determine whether they were suitable for inclusion. Discordances were resolved by consensus between the authors.

\section{Data Extraction}

For each study that was included, information was extracted concerning the study itself (authors, year of publication, and country of origin), the number and gender of patients evaluated, the number of thyroid lesions with histologic follow-up, and the number and rate of cancers and benign neoplasms detected.

\section{Statistical Analysis}

The prevalence of histologically proven cancers among the series of indeterminate nodules was obtained from each study using the following formula: number of cancers/number of thyroid nodules $\times 100$. For statistical pooling of the data, the DerSimonian and Laird method (a random-effects model) [22] was used. In this model, pooled data represent weighted averages related to the sample size of the individual studies. Pooled data are presented with $95 \%$ confidence intervals (Cls) and displayed using a forest plot. The $I^{2}$ index was used to quantify the heterogeneity among the studies, and significant heterogeneity was defined as an $I^{2}$ value $>50 \%$ [23]. The Egger test was carried out to evaluate the possible presence of significant publication bias [24]. Statistical analyses were performed using the StatsDirect statistical software (StatsDirect
Ltd., Altrincham, UK). Quality assessment was performed by the two authors according to QUADAS-2 [25].

\section{Results}

\section{Eligible Articles}

The comprehensive computer-based literature search yielded 235 articles, from which a review of titles and abstracts excluded 223 articles according to the above criteria. The full text of 12 articles eligible for the meta-analysis [15-21,26-30] was retrieved. Of these, five articles were excluded for overlapping [26] or unclear data [27-30]. Finally, seven studies reporting the use of CNB in thyroid nodules with previous indeterminate FNA results were initially selected for the systematic review, and then screened to validate their inclusion in the meta-analysis [15-21]. A flowchart of article selection is illustrated in Fig. 1.

\section{Qualitative Analysis}

The included studies were published between 2011 and 2016. They were authored by researchers from Korea or Italy. Five papers were retrospective, and the other two had a prospective design. The classification systems for thyroid cytology adopted by the authors (i.e., the Bethesda reporting system [4] and the Italian consensus for thyroid cytology classification [31]) were quite similar. Table 1 presents the main characteristics of the seven papers included in the review: overall, the studies included 1,187 nodules previously read as indeterminate on FNA, of which 582 had a histologic diagnosis. Of those 582 nodules, 214 were cancers.

\section{Diagram of flow}

Search of papers by using the terms thyroid and core and needle and biopsy



235 Articles retrieved and screened

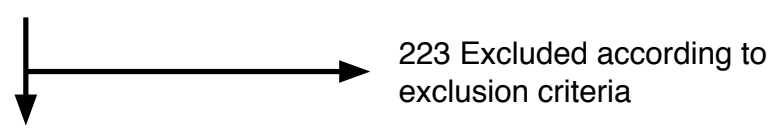

12 Articles initially eligible

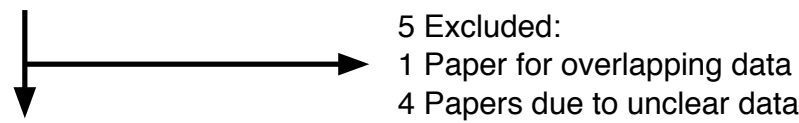

7 Papers finally included in the systematic review

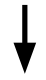

5 Papers included in the meta-analysis
Fig. 1. Flowchart of the search for published articles. Of the 235 papers initially found, 223 were excluded because they reported the use of core needle biopsy (CNB) in other contexts than indeterminate nodules (i.e., studies comparing the accuracy of CNB and fine-needle aspiration [FNA] in a series of patients with thyroid nodules with no prior FNA) or were case reports or review articles. Of the 12 studies determined to be eligible, four [27-30] were excluded due to unclear data (i.e., no clear histologic outcomes), and one [26] was excluded due to potential overlap of the study period with enrollment in another series [18]. 
Various study designs were used in the seven papers. First, Park et al. [15], in a prospective study, divided patients into three groups according to whether they underwent CNB $(n=54)$, a second round of FNA $(n=258)$, or diagnostic surgery $(n=62)$; their main finding was that the second-FNA group had a higher rate of non-diagnostic reports (39\%) than the CNB group. Another prospective study [16] selected a large series of atypia of undetermined significance/ follicular lesion of undetermined significance (AUS/FLUS) nodules to undergo CNB or repeat FNA, and the accuracy was $86 \%$ and $72 \%$, respectively. Moreover, inconclusive diagnoses (non-diagnostic or AUS/FLUS) on CNB were less common than on repeat FNA (26.7\% vs. $49.1 \%$, respectively). A study by the authors of the present review [17] attempted to make a diagnosis by sampling the nodule's capsule, enabling the lesions to be classified as encapsulated or not. Due to this almost investigational design, many benign encapsulated nodules (i.e., follicular adenomas) needed diagnostic surgery. These results were confirmed by a recent study [21]. A paper [18] investigated the clinical usefulness of combined CNB results and BRAF (V600E) analysis, and no significant improvement was recorded compared to the use of CNB alone. Another study by Trimboli et al. [20] applied the most accurate immunohistochemical (IHC) markers of indeterminate cytology (i.e., galectin-3, HBME-
1, and cytokeratin-19) to CNB samples; interestingly, the sensitivity and specificity of CNB increased from $79 \%$ to $100 \%$ and from $73 \%$ to $96 \%$, respectively, by adding this $\mathrm{HC}$ panel. Finally, $\mathrm{Na}$ et al. [19] enrolled a series of nodules with a prior AUS/FLUS assessment and performed both CNB and repeat FNA; the results showed higher diagnostic accuracy for CNB than for repeat FNA. Table 2 illustrates the quality assessment of the seven studies.

\section{Quantitative Analysis (Meta-analysis)}

Of the seven papers described above, two were excluded from the meta-analysis because they had experimental designs very different from the other studies $[17,21]$, and the remaining five $[15,16,18-$ 20], reporting 1,086 nodules of which 481 had a histologic diagnosis, were finally pooled (Table 3).

At the final postoperative histologic assessment, the cancer rate among the pooled series of indeterminate thyroid nodules was $34 \%$ (95\% Cl, 19 to 50 ), ranging from $20 \%$ to $63 \%$. This pooled finding showed heterogeneity $\left(I^{2}=92.4 \% ; 95 \% \mathrm{Cl}, 85.4\right.$ to 95.2$)$, with no publication bias (Egger: bias, $-5.03 ; 95 \% \mathrm{Cl},-48.63$ to 38.57 ; $\mathrm{P}=0.738$ ).

The rate of the correct diagnosis of CNB was $86 \%(95 \% \mathrm{Cl}, 72$ to 95$)$, ranging from $74 \%$ to $100 \%$. In this pooled analysis, we

Table 2. Quality assessment of the studies according to QUADAS-2

\begin{tabular}{|c|c|c|c|c|c|c|c|c|}
\hline \multirow[b]{2}{*}{ Reference } & \multicolumn{4}{|c|}{ Risk of bias } & \multicolumn{4}{|c|}{ Feasibility } \\
\hline & $\begin{array}{c}\text { Patient } \\
\text { selection }\end{array}$ & Study test & $\begin{array}{l}\text { Reference } \\
\text { standard }\end{array}$ & Timing & $\begin{array}{c}\text { Patient } \\
\text { selection }\end{array}$ & Study test & $\begin{array}{l}\text { Reference } \\
\text { standard }\end{array}$ & Timing \\
\hline Park et al. [15] & Unclear & $L R$ & $L R$ & $L R$ & Unclear & $L R$ & $L R$ & $L R$ \\
\hline Na et al. [16] & $L R$ & $L R$ & $L R$ & LR & $L R$ & $L R$ & $L R$ & $L R$ \\
\hline Nasrollah et al. [17] & $L R$ & $H R$ & $L R$ & Unclear & $L R$ & Unclear & $L R$ & Unclear \\
\hline Choi et al. [18] & $L R$ & LR & $L R$ & $L R$ & $L R$ & LR & $L R$ & $L R$ \\
\hline Na et al. [19] & $L R$ & $L R$ & $L R$ & $L R$ & $L R$ & $L R$ & $L R$ & $L R$ \\
\hline Trimboli et al. [20] & $L R$ & LR & $L R$ & LR & $L R$ & LR & $L R$ & $L R$ \\
\hline Han et al. [21] & $H R$ & $H R$ & $L R$ & $L R$ & $H R$ & $H R$ & $L R$ & LR \\
\hline
\end{tabular}

LR, low risk; HR, high risk.

Table 3. Performance of CNB in the five studies included in the meta-analysis

\begin{tabular}{|c|c|c|c|c|c|}
\hline \multirow{2}{*}{ Reference } & \multirow{2}{*}{ Cancer } & \multirow{2}{*}{ Benign } & \multicolumn{3}{|c|}{ Correct CNB diagnosis } \\
\hline & & & Total & Cancer & Benign \\
\hline Park et al. [15] & 11 & 42 & $53(100)$ & 11 & 42 \\
\hline Na et al. [16] & 65 & 39 & $77(74.0)$ & 51 & 26 \\
\hline Choi et al. [18] & 65 & 94 & $119(74.8)$ & 56 & 63 \\
\hline Na et al. [19] & 18 & 73 & $86(94.5)$ & 15 & 71 \\
\hline Trimboli et al. [20] & 19 & 55 & $55(74.3)$ & 15 & 40 \\
\hline
\end{tabular}

Values are presented as number (\%).

The performance of core needle biopsy (CNB) was only calculated in thyroid nodules with follow-up (see "Materials and Methods" section and Table 1). 
found both heterogeneity $\left(I^{2}=92.6 \% ; 95 \% \mathrm{Cl}, 86.2\right.$ to 95.3$)$ and significant publication bias (Egger: bias, $-9.02 ; 95 \% \mathrm{Cl},-15.17$ to $-2.88 ; \mathrm{P}=0.019$ ).

The rate of histologically proven cancers correctly diagnosed by CNB was $83 \%(95 \% \mathrm{Cl}, 76$ to 89 ), ranging from $78 \%$ to $100 \%$ (Fig. 2). In this analysis, we did not find heterogeneity $\left(\mathrm{I}^{2}=25 \% ; 95 \% \mathrm{Cl}\right.$, 0 to 72.3 ) or publication bias (Egger: bias, $0.24 ; 95 \% \mathrm{Cl},-6.66$ to 7.14; $P=0.918)$.

The percentage of nodules with benign post-surgical histology diagnosed correctly by CNB was $84 \%(95 \% \mathrm{Cl}, 65$ to 97$)$, ranging from $67 \%$ to $100 \%$ (Fig. 3). In the latter analysis, we found both heterogeneity $\left(I^{2}=93.4 \% ; 95 \% \mathrm{Cl}, 88.1\right.$ to 95.7$)$ and publication bias (Egger: bias $=-7.19 ; 95 \% \mathrm{Cl},-11.84$ to $-2.54 ; \mathrm{P}=0.016$ ).

\section{Discussion}

Indeterminate reports represent a non-negligible proportion of all thyroid FNA results. Traditionally, these lesions require diagnostic
Reliability of CNB to detect thyroid cancers

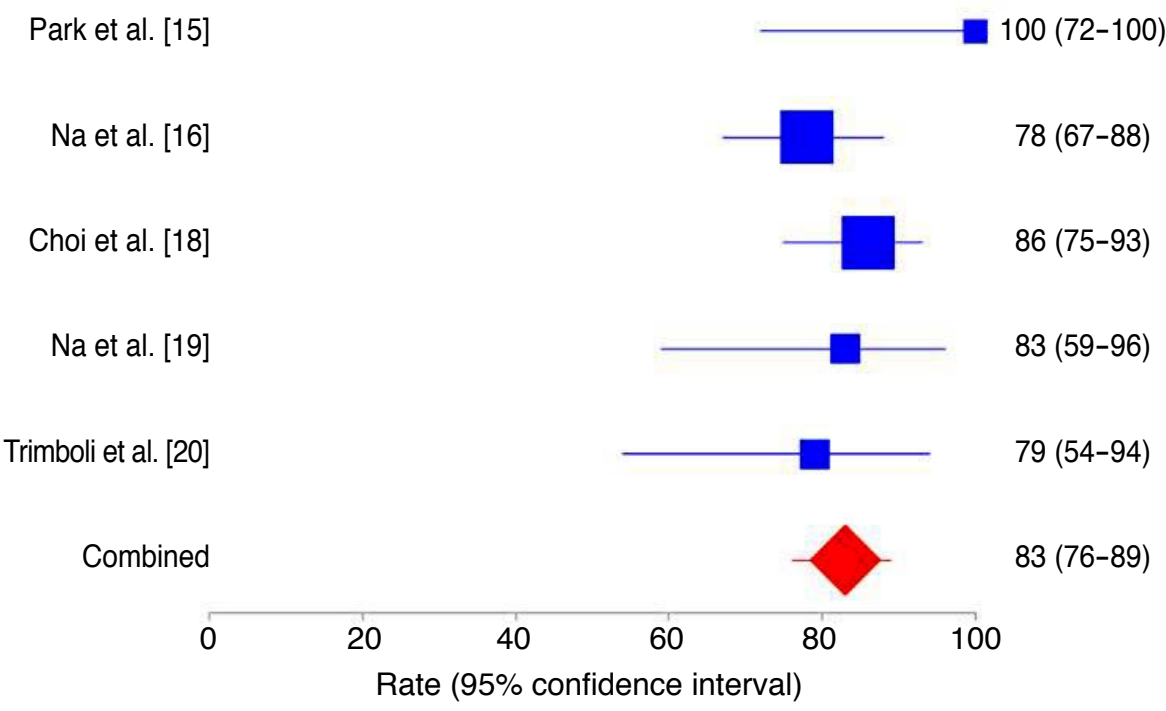

Reliability of CNB to detect benign thyroid nodules
$100(92-100)$

$67(50-81)$

$\mathrm{Na}$ et al. [16]

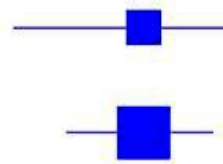

Choi et al. [18]

Na et al. [19]
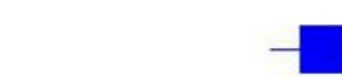

$97(90-100)$

Trimboli et al. [20]

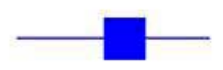

$73(59-84)$

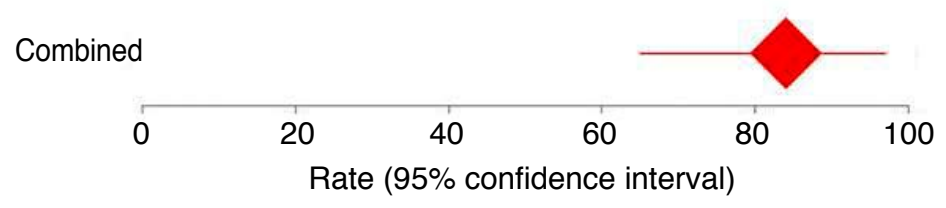

Fig. 2. Forest plot of the reliability of core needle biopsy (CNB) in detecting cancers in thyroid nodules with indeterminate fine-needle aspiration results. The rate of cancers correctly diagnosed by CNB was $83 \%$ (95\% confidence interval [Cl], 76 to $89)$, with neither heterogeneity $\left(I^{2}=25 \%\right.$; $95 \% \mathrm{Cl}, 0$ to 72.3$)$ nor publication bias (Egger: bias, $0.24 ; 95 \% \mathrm{Cl},-6.66$ to 7.14 , $\mathrm{P}=0.918)$.
Fig. 3. Forest plot of the reliability of core needle biopsy (CNB) in detecting benign lesions in thyroid nodules with indeterminate fine-needle aspiration results. The rate of benign nodules correctly assessed by CNB was 84\% (95\% confidence interval $[\mathrm{CI}], 65$ to 97), with significant heterogeneity $\left(I^{2}=93.4 \% ; 95 \%\right.$ $\mathrm{Cl}, 88.1$ to 95.7$)$ and publication bias (Egger: bias, $-7.19 ; 95 \% \mathrm{Cl}_{1}-11.84$ to $-2.54, \mathrm{P}=0.016)$. 
surgery, but benign findings are highly prevalent (i.e., up to $70 \%$ $80 \%$ ) at postoperative histology [5]. Since 2011, a number of singlecenter studies have investigated the role of CNB in discriminating cancers from benign neoplasms among indeterminate thyroid nodules, and this approach has been reported to be accurate [11]. Despite these findings, CNB has not been recommended in international guidelines. Herein, we systematically reviewed the studies on this topic, retrieved seven relevant studies [15-21], and conducted a meta-analysis of the results of five of those studies $[15,16,18-20]$. The cancer rate determined through postoperative histologic assessments was $34 \%$, and $86 \%$ of indeterminate nodules could be correctly identified by CNB. In particular, $83 \%$ of cancers and $84 \%$ of benign lesions were correctly diagnosed on CNB samples before surgery, and the pooled results of the reliability of CNB for detecting cancers was free of heterogeneity and publication bias. In our analysis, the rate of malignancy was slightly above than that one would expect in these indeterminate lesions, which could represent an indirect proof of the high quality of data in the present meta-analysis. To date, several diagnostic tools and procedures have been investigated as predictors of malignancy/benignancy in thyroid nodules cytologically classified as indeterminate [5-10]. Due to discordant results, the use of clinical, ultrasound, cytologic, molecular, or scintigraphic features has not been universally accepted as a preoperative diagnostic tool for these patients, and diagnostic surgery is still recommended in almost all cases $[1,2,4]$. In this context, the high sensitivity of CNB that we have demonstrated could become relevant in clinical practice because the chances of reducing unnecessary surgery are substantial [32]. In fact, a good/ excellent prognosis in patients with differentiated thyroid cancers with a preoperative indeterminate report has been recently shown by our group and in another study [33,34]. The use of CNB in such patients might save up to one-third of surgical costs [35].

Some differences in the study designs of the included papers were observed. Two studies $[16,20]$ conducted a second round of FNA alongside CNB in all patients. In both of those studies, the accuracy of the repeat FNA was lower than that of CNB. This agrees with the paper by Park et al. [15], in which some patients underwent CNB and others a second round of FNA. Unfortunately, the authors of those studies did not analyze the potential improvements in accuracy that could be achieved by combining the two types of biopsy. The latter approach allowed relevant data to be obtained from thyroid nodules with prior inadequate (i.e., Thy 1/category I) FNA reports [36]. Two other reports $[18,20]$ evaluated the potential improvement furnished by adding the analysis of tumor markers; Choi et al. [18] reported that BRAF analysis did not significantly increase the accuracy of $C N B$, in agreement with recent data from the literature [37]. On the contrary, a study [20] showed that
CNB reliability could be improved by evaluating the expression of galectin-3 and HBME-1 in microhistologic specimens. All in all, the accuracy of CNB seems to be satisfactory, even if some nodules may not be properly assessed and might still require diagnostic surgery. Future studies in which other clinical or histologic procedures, such as ultrasonography, ${ }^{99 \mathrm{~m}} \mathrm{Tc}$-sestamibi scintigraphy, repeat FNA, and immunohistochemistry, are performed alongside CNB could yield information on ways to improve the accuracy of this new biopsy technique.

A relevant meta-analysis of the reliability of CNB in indeterminate thyroid nodules was published by Suh et al. [38]. Herein, we adopted a different search algorithm, so our results are not perfectly comparable to those obtained by Suh et al. [38]. Additionally, in that article, the results of CNB were grouped into the six categories of the Bethesda system, whereas we only considered malignant and benign outcomes. However, the high accuracy of CNB was demonstrated in both papers, and, notably, very low rates of inconclusive results and complications from CNB were reported by Suh et al. [38].

To date, several protocols for using CNB in thyroid nodules have been described $[39,40]$. As discussed above, some papers reported attempts to make a diagnosis by sampling the nodule's capsule $[17,21]$. Other authors showed that CNB enabled a diagnosis to be obtained in thyroid nodules with specific features mimicking malignant lesions [41]. The current guidelines contain limited recommendations for thyroid CNB. The National Cancer Institute [42], American Association of Clinical Endocrinologists/American College of Endocrinology/Associazione Medici Endocrinologi (AACE/ACE/ AME) [1], and the KSThR [43] propose CNB for thyroid nodules with previous non-diagnostic FNA results. Additionally, the AACE/ACE/ AME [1], British Thyroid Association [2], and KSThR [43] suggest CNB for lymphoma, anaplastic carcinoma, medullary carcinoma, and metastasis to the thyroid. Remarkably, the rate of complications reported from thyroid CNB is very low $[12,38]$. As a consequence, we feel that the present data strongly support the use of CNB in thyroid nodules with prior indeterminate FNA.

Some minor limitations of the present data should be discussed. The final number of nodules included in the meta-analysis (481 cases) is suboptimal; a larger number would be desirable. In our analysis, the rate of malignancy was in line with what one would expect in these indeterminate lesions, which could represent an indirect proof of the high quality of data in the present metaanalysis this discrepancy might reflect a minor bias in the initial selection of thyroid nodules for FNA performed by the authors of the studies we analyzed. Finally, the authors of the retrieved papers were from only two countries (Korea and Italy); other international experiences should extend these findings. 
The present meta-analysis presents evidence that CNB can correctly diagnose most nodules previously read as indeterminate on FNA. These findings should be considered for the management of such patients. Performing other procedures (i.e., clinical or histologic) alongside CNB might significantly increase the reliability of this biopsy technique, and this possibility should be investigated in future studies.

ORCID: Pierpaolo Trimboli: http://orcid.org/0000-0002-2125-4937; Luca Giovanella: http://orcid.org/0000-0003-0230-0974

\section{Conflict of Interest}

No potential conflict of interest relevant to this article was reported.

\section{Supplementary Material}

Supplementary Table 1. PRISMA 2009 checklist (https://doi. org/10.14366/usg/17066).

\section{References}

1. Gharib H, Papini E, Paschke R, Duick DS, Valcavi R, Hegedus L, et al. American Association of Clinical Endocrinologists, Associazione Medici Endocrinologi, and EuropeanThyroid Association medical guidelines for clinical practice for the diagnosis and management of thyroid nodules. Endocr Pract 2010;16 Suppl 1:1-43.

2. Perros P, Boelaert K, Colley S, Evans C, Evans RM, Gerrard G, et al. Guidelines for the management of thyroid cancer. Clin Endocrinol (Oxf) 2014;81 Suppl 1:1-122.

3. Baloch ZW, Fleisher S, LiVolsi VA, Gupta PK. Diagnosis of "follicular neoplasm": a gray zone in thyroid fine-needle aspiration cytology. Diagn Cytopathol 2002;26:41-44.

4. Cibas ES, Ali SZ. The Bethesda System for Reporting Thyroid Cytopathology. Thyroid 2009;19:1159-1165.

5. Trimboli P, Treglia G, Guidobaldi L, Saggiorato E, Nigri G, Crescenzi A, et al. Clinical characteristics as predictors of malignancy in patients with indeterminate thyroid cytology: a meta-analysis. Endocrine 2014;46:52-59.

6. Trimboli P, Virili C, Romanelli F, Crescenzi A, Giovanella L. Galectin-3 performance in histologic a cytologic assessment of thyroid nodules: a systematic review and meta-analysis. Int J Mol Sci 2017;18:E1756.

7. Trimboli P, Condorelli E, Catania A, Sorrenti S. Clinical and ultrasound parameters in the approach to thyroid nodules cytologically classified as indeterminate neoplasm. Diagn Cytopathol 2009;37:783-785.

8. Trimboli P, Fulciniti F, Zilioli V, Ceriani L, Giovanella L. Accuracy of international ultrasound risk stratification systems in thyroid lesions cytologically classified as indeterminate. Diagn Cytopathol
2017;45:113-117.

9. Saggiorato $E$, Angusti $T$, Rosas $R$, Martinese $M$, Finessi $M$, Arecco $F$, et al. 99mTc-MIBI Imaging in the presurgical characterization of thyroid follicular neoplasms: relationship to multidrug resistance protein expression. J Nucl Med 2009;50:1785-1793.

10. Giovanella L, Ceriani L, Treglia G. Role of isotope scan, including positron emission tomography/computed tomography, in nodular goitre. Best Pract Res Clin Endocrinol Metab 2014;28:507-518.

11. Trimboli P, Crescenzi A. Thyroid core needle biopsy: taking stock of the situation. Endocrine 2015;48:779-785.

12. Nasrollah N, Trimboli P, Rossi F, Amendola S, Guidobaldi L, Ventura C, et al. Patient's comfort with and tolerability of thyroid core needle biopsy. Endocrine 2014;45:79-83.

13. Na DG, Baek JH, Jung SL, Kim JH, Sung JY, Kim KS, et al. Core needle biopsy of the thyroid: 2016 consensus statement and recommendations from Korean Society of Thyroid Radiology. Korean J Radiol 2017;18:217-237.

14. Liberati A, Altman DG, Tetzlaff J, Mulrow C, Gotzsche PC, loannidis JP, et al. The PRISMA statement for reporting systematic reviews and meta-analyses of studies that evaluate health care interventions: explanation and elaboration. PLoS Med 2009;6:e1000100.

15. Park KT, Ahn SH, Mo JH, Park YJ, Park DJ, Choi SI, et al. Role of core needle biopsy and ultrasonographic finding in management of indeterminate thyroid nodules. Head Neck 2011;33:160-165.

16. Na DG, Kim JH, Sung JY, Baek JH, Jung KC, Lee $H$, et al. Coreneedle biopsy is more useful than repeat fine-needle aspiration in thyroid nodules read as nondiagnostic or atypia of undetermined significance by the Bethesda System for Reporting Thyroid Cytopathology. Thyroid 2012;22:468-475.

17. Nasrollah N, Trimboli P, Guidobaldi L, Cicciarella Modica DD, Ventura C, Ramacciato G, et al. Thin core biopsy should help to discriminate thyroid nodules cytologically classified as indeterminate: a new sampling technique. Endocrine 2013;43:659-665.

18. Choi SH, Baek JH, Lee JH, Choi YJ, Song DE, Chung KW, et al. Evaluation of the clinical usefulness of BRAFV600E mutation analysis of core-needle biopsy specimens in thyroid nodules with previous atypia of undetermined significance or follicular lesions of undetermined significance results. Thyroid 2015;25:897-903.

19. Na DG, Min HS, Lee H, Won JK, Seo HB, Kim JH. Role of core needle biopsy in the management of atypia/follicular lesion of undetermined significance thyroid nodules: comparison with repeat fine-needle aspiration in subcategory nodules. Eur Thyroid J 2015;4:189-196.

20. Trimboli P, Guidobaldi L, Amendola S, Nasrollah N, Romanelli F, Attanasio D, et al. Galectin-3 and HBME-1 improve the accuracy of core biopsy in indeterminate thyroid nodules. Endocrine 2016;52:39-45.

21. Han S, Shin JH, Hahn SY, Oh YL. Modified Core Biopsy Technique 
to increase diagnostic yields for well-circumscribed indeterminate thyroid nodules: a retrospective analysis. AJNR Am J Neuroradiol 2016;37:1155-1159.

22. DerSimonian R, Laird N. Meta-analysis in clinical trials. Control Clin Trials 1986;7:177-188.

23. Higgins JP, Thompson SG, Deeks JJ, Altman DG. Measuring inconsistency in meta-analyses. BMJ 2003;327:557-560.

24. Duval S, Tweedie R. Trim and fill: A simple funnel-plot-based method of testing and adjusting for publication bias in metaanalysis. Biometrics 2000;56:455-463.

25. Whiting PF, Rutjes AW, Westwood ME, Mallett S, Deeks JJ, Reitsma $J B$, et al. QUADAS-2: a revised tool for the quality assessment of diagnostic accuracy studies. Ann Intern Med 2011;155:529-536.

26. Choi YJ, Baek JH, Ha EJ, Lim HK, Lee JH, Kim JK, et al. Differences in risk of malignancy and management recommendations in subcategories of thyroid nodules with atypia of undetermined significance or follicular lesion of undetermined significance: the role of ultrasound-guided core-needle biopsy. Thyroid 2014;24:494501.

27. Hakala T, Kholova I, Sand J, Saaristo R, Kellokumpu-Lehtinen P. A core needle biopsy provides more malignancy-specific results than fine-needle aspiration biopsy in thyroid nodules suspicious for malignancy. J Clin Pathol 2013;66:1046-1050.

28. Hahn SY, Shin JH, Han BK, Ko EY, Ko ES. Ultrasonography-guided core needle biopsy for the thyroid nodule: does the procedure hold any benefit for the diagnosis when fine-needle aspiration cytology analysis shows inconclusive results? Br J Radiol 2013;86:20130007.

29. Min HS, Kim JH, Ryoo I, Jung SL, Jung CK. The role of core needle biopsy in the preoperative diagnosis of follicular neoplasm of the thyroid. APMIS 2014;122:993-1000.

30. Yoon RG, Baek JH, Lee JH, Choi YJ, Hong MJ, Song DE, et al. Diagnosis of thyroid follicular neoplasm: fine-needle aspiration versus core-needle biopsy. Thyroid 2014;24:1612-1617.

31. Fadda G, Basolo F, Bondi A, Bussolati G, Crescenzi A, Nappi O, et al. Cytological classification of thyroid nodules: proposal of the SIAPEC-IAP Italian Consensus Working Group. Pathologica 2010;102:405-408.

32. Sebo TJ. What are the keys to successful thyroid FNA interpretation?
Clin Endocrinol (Oxf) 2012;77:13-17.

33. Trimboli P, Bongiovanni M, Rossi F, Guidobaldi L, Crescenzi A, Ceriani $L$, et al. Differentiated thyroid cancer patients with a previous indeterminate (Thy 3) cytology have a better prognosis than those with suspicious or malignant FNAC reports. Endocrine 2015;49:191-195.

34. Rago T, Scutari M, Latrofa F, Loiacono V, Piaggi P, Marchetti I, et al. The large majority of 1520 patients with indeterminate thyroid nodule at cytology have a favorable outcome, and a clinical risk score has a high negative predictive value for a more cumbersome cancer disease. J Clin Endocrinol Metab 2014;99:3700-3707.

35. Trimboli P, Nasrollah N, Amendola S, Crescenzi A, Guidobaldi L, Chiesa $C$, et al. A cost analysis of thyroid core needle biopsy vs. diagnostic surgery. Gland Surg 2015;4:307-311.

36. Samir AE, Vij A, Seale MK, Desai G, Halpern E, Faquin WC, et al. Ultrasound-guided percutaneous thyroid nodule core biopsy: clinical utility in patients with prior nondiagnostic fine-needle aspirate. Thyroid 2012;22:461-467.

37. Trimboli P, Treglia G, Condorelli E, Romanelli F, Crescenzi A, Bongiovanni $M$, et al. BRAF-mutated carcinomas among thyroid nodules with prior indeterminate FNA report: a systematic review and meta-analysis. Clin Endocrinol (Oxf) 2016;84:315-320.

38. Suh CH, Baek JH, Park C, Choi YJ, Lee JH. The role of core needle biopsy for thyroid nodules with initially indeterminate results on previous fine-needle aspiration: a systematic review and metaanalysis. AJNR Am J Neuroradiol 2017;38:1421-1426.

39. Baek JH. Current status of core needle biopsy of the thyroid. Ultrasonography 2017;36:83-85.

40. Jung CK, Baek JH. Recent advances in core needle biopsy for thyroid nodules. Endocrinol Metab (Seoul) 2017;32:407-412.

41. Lee HY, Baek JH, Ha EJ, Park JW, Lee JH, Song DE, et al. Malignantlooking thyroid nodules with size reduction: core needle biopsy results. Ultrasonography 2016;35:327-334.

42. Baloch ZW, Cibas ES, Clark DP, Layfield LJ, Ljung BM, Pitman MB, et al. The National Cancer Institute Thyroid fine needle aspiration state of the science conference: a summation. Cytojournal 2008;5:6.

43. Baek JH, Na DG, Lee JH, Jung SL, Kim JH, Sung JY, et al. Core needle biopsy of thyroid nodules: consensus statement and recommendations. J Korean Soc Ultrasound Med 2013;32:95-102. 